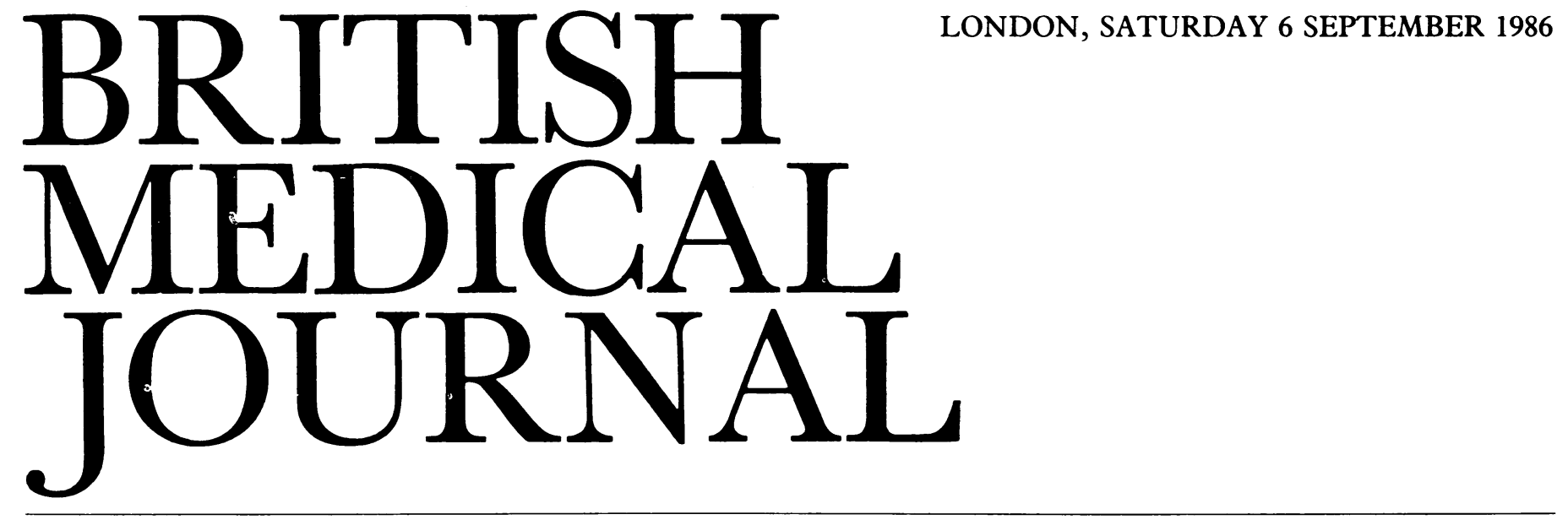

\title{
Staying one jump ahead of resistant Staphylococcus aureus
}

Strains of methicillin resistant Staphylococcus aureus have caused outbreaks of colonisation and infection in intensive care and other special units in hospitals throughout the world. Difficulties in controlling cross infection and the alarm in having only one reserve antibiotic available for treatment have led to the publication of guidelines for control by a combined working party of the Hospital Infection Society and the British Society for Antimicrobial Chemotherapy. Because of the ease with which these strains spread the guidelines call them epidemic methicillin resistant $S$ aureus. The stringent guidelines were aimed primarily at the strain currently causing outbreaks in London and south east England, ${ }^{2}$ but they can be adapted for other strains and other outbreaks.

Resistance to methicillin appeared in $S$ aureus in $1961^{3}$ and prevents treatment by flucloxacillin and other isoxazolyl penicillins, which replaced methicillin. Outbreaks of hospital infection occurred in the $1960 \mathrm{~s}^{4}$ but then declined. ${ }^{5}$ In 1976 the first outbreak of hospital infection with a strain resistant to both methicillin and gentamicin was described in London, ${ }^{6}$ and a few years later in Australia there began a nationwide outbreak of hospital infection with $S$ aureus resistant to penicillin, methicillin, gentamicin, cephalosporins, erythromycin, and tetracyclines. ${ }^{78}$ These organisms were always susceptible to vancomycin and sometimes susceptible to fusidic acid, rifampicin, and chloramphenicol. Since then outbreaks have been described in Europe, ${ }^{9-12}$ the United States, ${ }^{13}$ South Africa, and the Middle East.

It has been suggested that the genetic baggage required by $S$ aureus for mutiple antibiotic resistance might limit virulence and the ability to transfer between patients. ${ }^{14}$ However, some strains of methicillin resistant $S$ aureus have shown transmissibility ${ }^{15}$ and virulence ${ }^{16-18}$ comparable to those of organisms that are methicillin sensitive, while others seem less transferable and virulent. ${ }^{19}$ Colonisation with epidemic resistant $S$ aureus is found at usual sites for $S$ aureus in both patients and staff-that is, the nose and skin lesions. ${ }^{20}$ Colonisation is more common than infection, but osteomyelitis, ${ }^{21}$ endocarditis, pneumonia, urinary tract infection, infection of prostheses, and septicaemia ${ }^{9}{ }^{15}$ have all been reported.

Epidemic resistant $S$ aureus usually enters a hospital via a patient transferred from an affected hospital, ${ }^{11}{ }^{22-24}$ and the patient may not be known to be so colonised or infected. Staff also transport strains between hospitals-for instance, a surgeon with eczema ${ }^{25}$ and an agency nurse. ${ }^{26}$ Once within a hospital, epidemic resistant $S$ aureus spreads like other $S$ aureus, ${ }^{27}{ }^{28}$ predominantly by contact transfer on the hands. ${ }^{29}$ Organisms from a contaminated surface or wound, or nose, will transiently adhere to the hands and then be deposited where they to'lch if the hands are not washed. $S$ aureus can be carried on clothing and survives in dust,${ }^{30}$ and contamination of bed clothing and ward furniture also occurs.

The first difficulty in controlling epidemic resistant $S$ aureus is in detecting the organism-extensive colonisation of patients may have taken place before the first isolate is found. By then it may be hard to discover how many patients and staff are affected. After discovery the aim is eradication of the organism from the hospital. This will be easier if there are only one or two cases, and with larger numbers containment by limiting further spread may be all that is possible. Facilities for washing the hands and for isolating patients are often inadequate, and ensuring agreement for precautions may be difficult. More difficult still may be to get everybody to cooperate, but this is vital for success. A control of infection committee should provide support, but the diplomatic powers of the infection control officer will be tested.

The guidelines recommend that a known case should be isolated on admission to hospital, as should all patients from affected hospitals while they are being screened. This implies forewarning from the referring hospital and some means of identifying exposed, colonised, or infected patients. Marking the casenotes of affected patients should help, and in Britain a pilot surveillance scheme to record affected hospitals has been started by the Communicable Disease Surveillance Centre.

Cases detected when already in hospital should be isolated, with priority given to patients with clinical infection or exfoliative skin conditions. Other exposed patients and staff must be screened by swabs of the anterior nares and other skin carriage sites, and isolated and treated if positive. The guidelines suggest that staff nasal carriers can return to work after one day of treatment, but wider carriage requires clearance before return. Staff moving between affected and unaffected hospitals should also be screened. To prevent further spread between patients, staff and visitors should wash their hands with an antiseptic detergent or an alcoholic 
hand rub and use disposable plastic aprons or gowns before and after contact with an affected patient or his immediate environment. Patients should use an antiseptic detergent for washing and bathing.

The working party favours a dedicated unit for isolating patients with epidemic resistant $S$ aureus. Failing that, it preferred a small ward with designated staff to side wards or rooms in general wards, where staff do not understand or have time for infection control. This recommendation is supported by the experience from several outbreaks ${ }^{11}{ }^{12}{ }^{31} 32$; and in one hospital spread increased when a unit was closed and reduced again when it was reopened. The cost of such a unit must be weighed against the lengthened hospital stay of more cases without one.

Treatment to eliminate $S$ aureus from carriers and cases is unreliable at best, and epidemic resistant $S$ aureus responds poorly to nasal antiseptics. ${ }^{32}$

The guidelines suggest mupirocin for nasal carriage ${ }^{12}{ }^{33}$ and to treat the organism in eczema and pressure sores. Clearance may be declared only after three weekly negative swabs from the nose, axillae, fingers, perineum, and lesions. Clearly, the doctor in charge of a patient should on discharge tell the general practitioner or the infection control officer of the receiving hospital.

Consultant Microbiologist,

P J SANDERSON

Edgware General Hospital,

Edgware,

Middlesex HA8 0AD

1 Combined working party of the Hospital Infection Society and British Society for Antimicrobial Chemotherapy. Guidelines for the control of epidemic methicillin resistant Staphylococcus Chemotherapy. Guidelines for the cont

2 Marples RR, Richardson JF, de Saxe MJ. Bacteriological characters of strains of Staphylococcus aureus submitted to a reference laboratory related to methicillin resistance. f Hyg (Camb) 1986;96:217-23.

3 Jevons MP. "Celbenin" resistant staphylococci. Br Med $\mathcal{f} 1961$;i:124-5.

4 Anonymous. Methicillin resistant staphylococci. [Editorial]. Lancet 1968;ii:759.

5 Ayliffe GAJ, Lilly HA, Lowbury EJL. Decline of the hospital staphylococcus? Incidence of multiresistant Staphylococcus aureus in three Birmingham hospitals. Lancet 1979;i:538-41.

6 Shanson DC, Kensit JG, Duke R. Outbreak of hospital infection with a strain of Staphylococcus aureus resistant to gentamicin and methicillin. Lancet 1976; ii:1347-8.

7 Pavillard R, Harvey K, Douglas D, et al. Epidemic of hospital-acquired infection due to methicillin-resistant Staphylococcus aureus in major Victorian hospitals. Med $\mathcal{F}$ Aust 1982; 451-4.

8 McDonald M, Hurse A, Sim KN. Methicillin-resistant Staphylococcus aureus in bacteraemia. Med F A ust 1981;ii:191-4.

9 Med $\mathrm{f}$ Aust $1981 ; \mathrm{in}: 191.4$. Hone R, Cafferkey M, Keane CT, et al. Bacteraemia
Staphylococcus aureus. $\mathcal{F}$ Hosp Infect 1981;2:119-26.

10 Braph JM, Noouse a London hospital. Lancet 1985 ;i:1493-5.

11 Shanson DC, Johnstone D, Midgley J. Control of a hospital outbreak of methicillin-resistant Staphylococcus aureus infection: value of an isolation unit. $\mathcal{F}$ Hosp Infect 1985;6:285-92.

12 Dacre J, Emmerson A, Jenner EA. Gentamicin-methicillin-resistant Staphylococcus aureus: epidemiology and containment of an outbreak. I Hosp Infect 1986;7:130-6.

13 Boyce JM, Causey WA. Increasing occurrence of methicillin-resistant Staphylococcus aureus in the United States. Infection control 1982;3:377-83.

14 Lacey RW, Chopra I. The effect of plasmid carriage on the virulence of Staphylococcus aureas. $f$ Med Microbiol 1975;8:137-47.

15 Thompson RL, Cabezudo I, Wensel RP. Epidemiology of nosocomial infection caused by methicillin-resistant Staphylococcus aureus. Ann Intern Med 1982;97:309-17.

16 Crossley K, Landesman B, Zaske D. An outbreak of infections caused by strains of Staphylococcus aureus resistant to methicillin and aminoglycosides. $\mathcal{F}$ Infect Dis 1979;139. 280-7.

17 Boyce JM, Landry M, Deetz TR, DuPont HL. Epidemiologic studies of an outbreak of nosocomial methicillin-resistant Staphylococcus aureas infections. Infection Control 1981;2: nosocom.

18 Peacock JE Jr, Moorman DR, Wenzel RP, Mandell GL. Methicillin-resistant Staphylococcus aureus: microbiological characteristics, antimicrobial susceptibilities and assessment of virulence of an epidemic strain. $\mathcal{F}$ Infect Dis 1981;144:575-82.

19 Lacey RW, Barr KW, Barr VE, Inglis TJ. Properties of methicillin resistant Staphylococcus aureus colonising patients in a burns unit. $\mathcal{F}$ Hosp Infect 1986;7:137-48

20 Williams REO. Skin and nose carriage of bacteriophage types of Staphylococcus aureus. Fournal of Pathology and Bacteriology 1946;48:259-70.

21 Fitzpatrick DJ, Cafferkey MT, Toner M, Beattie T, Keane CT. Osteomyelitis with methicillin resistant Staphylococcus aureus. $\mathcal{F}$ Hosp Infect 1986;1:24-30

22 Price EH, Brain A, Dickson JAS. An outbreak of infection with a gentamicin and methicillinresistant Staphylococcus aureus in a neonatal unit. $\mathcal{F}$ Hosp Infect 1980:1:221-8.

23 Saroglou G, Cromer M, Bisno AL. Methicillin-resistant Staphylococcus aureus: interstate spread of nosocomial infections with emergence of gentamicin-methicillin resistant strains. Infection control 1980;1:81-9.

24 Townsend DE, Ashdown N, Annear DI, Pearman JW, Grubb WB. Genetic analysis of methicillin-resistant Staphylococcus aureus from a Western Australian hospital. $\mathcal{f}$ Hosp Infect 1984;5:417-24.

25 Shanson DC, McSwiggan DA. Operating theatre acquired infection with a gentamicin-resistant strain of Staphyloccus aureus: outbreaks in two hospitals attributable to one surgeon. $\mathcal{f}$ Hosp Infect 1980;1:171-2.
26 Cookson BD, Farrington M, Webster M, Phillips I. Methicillin resistant Staphylococcus aureus. Lancet 1985;ii:218-9.

27 Hare R, Ridley M. Further studies in the transmission of Staphylococcus aureus. Br Med $\mathcal{J}$ 1958;i:69-76.

28 Shooter RA, Smith MA, Griffiths JD, et al. Spread of staphylococci in a surgical ward. Br Med $\mathcal{F}$ 1958;i:607-13.

29 King K, Brady L, Thomson M, Harkness JL. Antibiotic-resistant staphylococci in a teaching hospital. Med f Aust 1982;ii:461-5.

30 Lidwell OM, Lowbury EJ. The survival of bacteria in dust. I. The distribution of bacteria in floor dust. $\mathcal{F}$ Hyg (Lond) 1950;48:6-12.

31 Selkon JB, Stokes ER, Ingham HR. The role of an isolation unit in the control of hospital infection with methicillin-resistant staphylococci. I Hosp Infect 1980;1:41-6.

32 Pearman JW, Christiansen KJ, Annear DI, et al. Control of methicillin-resistant Staphylococcus aureus (MSRA) in an Australian metropolitan teaching hospital complex. Med $\mathcal{J}$ Aust aureus (MSRA)
$1985 ; 142: 103-8$.

33 Casewell MR, Hill RLR. Elimination of nasal carriage of Staphylococcus aureus with mupirocin ('pseudominic acid')—a controlled trial. I Antimicrob Chemother 1986;17:365-72.

\section{Murdering while asleep}

A person who commits a criminal act while asleep is not conscious of his actions and cannot be held legally responsible for them. The law calls these acts sane automatisms, and Lord Justice Lawton has described them as a "quagmire of the law, seldom entered save by those in desperate need of some kind of a defence." Recently defence counsels have shown less reluctance to enter this quagmire. It is therefore essential that the court examines critically any medical evidence presented in such cases.

Is it possible for people to act violently, and even kill, during sleep? Yes-but only exceptionally..$^{2.5}$ A night's sleep consists of cycles of slow wave sleep and rapid eye movement (REM or dreaming) sleep, alternating in periods of about 90 minutes. What we think of as dreaming, with complex imagery and a narrative, occurs in REM sleep. Dreams and nightmares are usually easily and immediately recalled on wakening. Aggression is common in dreams ${ }^{6}$ (occurring in over half the dreams in one American study) but cannot be acted out because the body is paralysed during REM sleep. During the waking stages of a dream movements may occur, but clear consciousness returns too quickly for any coordinated violent act to be committed. Crimes after a nightmare are usually motivated and cannot easily be attributed to a confusional state.

Mental experiences do occur during slow wave sleep but are quite different from typical dreams. The imagery is poorly formed and non-narrative. If the sleeper is aroused, clear consciousness does not return immediately-it may take five or 10 minutes for him to become fully awake. Finally, there is poor memory or no recall, of the experience. The body is not paralysed during slow wave sleep, and it is during this phase that sleep walking, sleep talking, and night terrors occur. Sleep walking and night terrors usually occur in the deepest phase of slow wave sleep, within two hours of falling asleep.

Highly complex, coordinated movements are possible in both sleep walking and night terrors. There are reports of sleep walkers firing guns, driving cars, walking down fire escapes, and committing murders. Night terrors differ from sleep walking in that the dreamer shows intense emotional arousal: heart rate and respiratory rate accelerate, and there is profuse perspiration. The sleeper may scream piercingly and make physical movements, such as sitting up, or, very occasionally, assaulting a sleeping partner, or fleeing from the room. Night terrors have all the characteristics of experiences during slow wave sleep. Mental content usually consists of falling, being crushed, trapped, or abandoned, dying, choking, or being attacked, although rarely it may have a thin narrative quality. 